\title{
Olfactory mucosa in herpes simplex encephalitis
}

\author{
J.A. T W OMEY, CHR IST INE M.BARKER, G. ROB I NSON, \\ A N D D. A . H O W E L L
}

From the Departments of Neurology, Virology, and Neuropathology of the Derbyshire Royal Infirmary, and Department of Pathology, University Hospital, Nottingham

SUMMARY The olfactory mucosa was examined in three patients dying from herpes simplex encephalitis. It showed changes attributed to infection by the herpes simplex virus. It is suggested that in some patients encephalitis may be a complication of infection of the olfactory mucosa.

It was suggested by Hurst (1936) that the localisation of early lesions in certain forms of viral encephalitis within the limbic system indicated that the virus invaded the brain through the olfactory nerves and their central connections. In mice, herpes simplex and other viruses have been shown to invade the brain in this way (Johnson and Mims, 1968), and Legg (1975) has suggested that herpes simplex probably does so in man. The virus has been isolated from the olfactory mucosa in a patient dying from herpes simplex encephalitis (Flewitt, 1973).

We report observations on the olfactory mucosa of three patients dying from herpes simplex encephalitis.

\section{Case reports}

CASE 1

In April 1975 a 63 year old man developed a series of focal convulsions in the left limbs and a left hemiparesis. He became confused and then comatose after five days, dying after 19 days. The cerebrospinal fluid (CSF) contained 42 leucocytes per $\mathrm{mm}^{3}(24 \%$ polymorphonuclear cells and $76 \%$ lymphocytes).

At the postmortem examination the brain was soft and swollen and the convolutions flat. Histological sections from many areas showed patchy necrosis of the cortex, and pallor and oedema of the underlying white matter. Perivascular cuffing with lymphocytes was prominent, and lymphocytes were scattered through some of the necrotic cortex.

Address for reprint requests: Dr J. A. Twomey, Department of Neurology, Derbyshire Royal Infirmary, Derby DE1 $2 Q Y$.

Accepted 17 April 1979

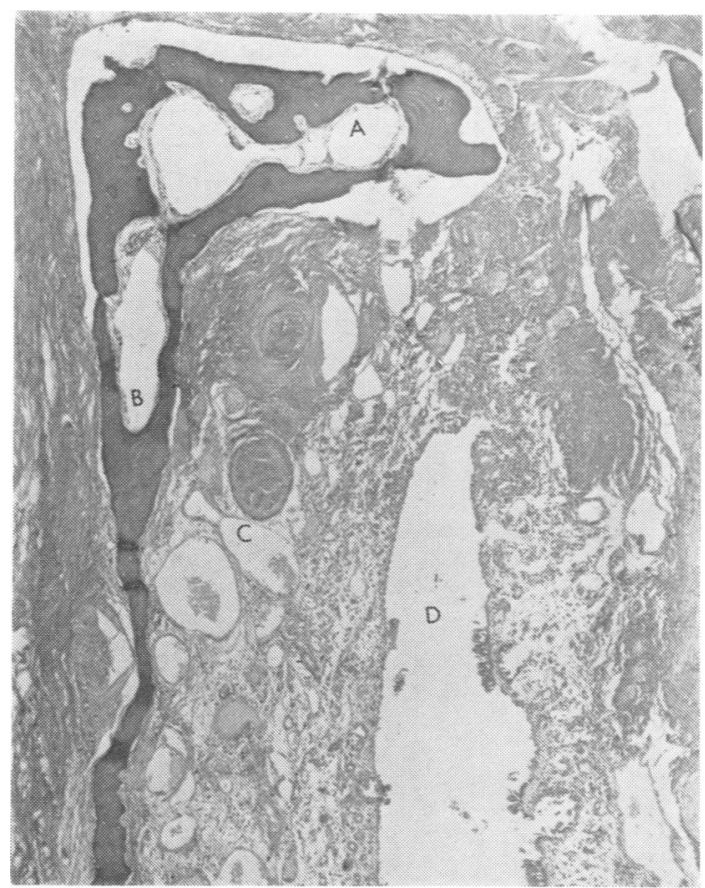

Fig. 1 Section through the olfactory space (case 3). Stained by haematoxylin and Van Giesson, original magnification $\times 36$. $A$ is the cribiform plate; $B$ is bone of the superior concha in the lateral wall; $C$ is blood within and around the perineural sheaths of two olfactory nerves; $D$ is the olfactory space lined with ulcerated and surviving epithelium.

Herpes simplex virus was demonstrated by indirect immunofluorescence in a brain biopsy. It was grown on tissue culture from a throat swab and from the brain biopsy sample during life, and from both hemispheres after death. 
CASE 2

In August 1975 a 40 year old man became ill with fever, headache, and confusion progressing to coma in two days. He died on the fourth day. The CSF contained 140 leucocytes per $\mathrm{mm}^{3}$. $(65 \%$ polymorphonuclear cells and $35 \%$ lymphocytes.)

At the postmortem examination the convolutions were flat, and the left temporal lobe was swollen. The paraolfactory areas and the parahippocampal gyri of both hemispheres were inflamed. Histological sections of the brain showed patchy cortical necrosis in these areas associated with perivascular collections of lymphocytes and clusters of lymphocytes in the cortex. Some nuclear inclusion bodies were found.

Herpes simplex virus was demonstrated by indirect immunofluorescence in a brain biopsy sample during life, though it failed to grow in tissue culture. It was grown from the left olfactory bulb and the paraolfactory area, after death.

\section{CASE 3}

In January 1978 a 53 year old woman became ill with headaches, hallucinations, and confusion. She had a generalised convulsion and became comatose on the fifth day, dying on the sixteenth day of the illness. Her CSF contained 10 leucocytes per $\mathrm{mm}^{3}(60 \%$ polymorphonuclear cells and $40 \%$ lymphocytes).

At the postmortem examination the brain was soft and swollen with flat convolutions. There was haemorrhagic necrosis of the posterior part of the right parahippocampal gyrus. Histological sections showed perivascular cuffing with lymphocytes in the grey and white matter of both temporal and frontal lobes. There was widespread and gross destruction of neurones. Small haemorrhages and nuclear inclusion bodies were found.

Herpes simplex virus was grown from the brain biopsy sample during life and from both temporal lobes after death.

\section{Changes in olfactory mucosa}

During each of the postmortem examinations a rectangular piece of bone, about $30 \mathrm{~mm} \times 20 \mathrm{~mm}$ was cut out of the floor of the anterior fossa of the skull to include the cribriform plate on each

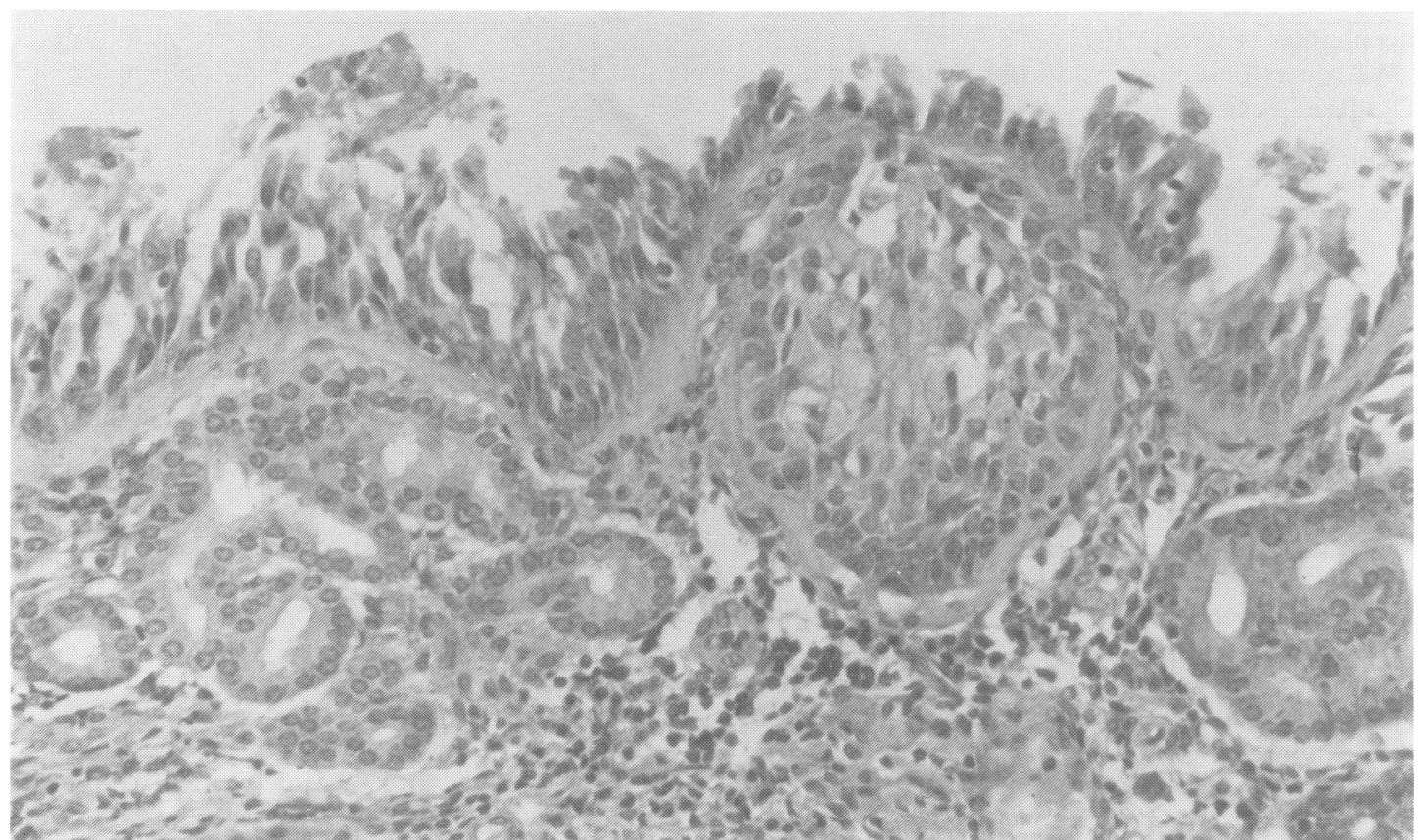

Fig 2 Section of olfactory mucosa (case 1) stained with phloxine tartrazine, original magnification $\times 400$. The surface epithelium appears ragged and the cells in diverticulum are swollen and dying. They contain nuclear inclusion bodies. The Bowman's glands appear normal but the lamina propria is infiltrated with lymphocytes and plasma cells. 


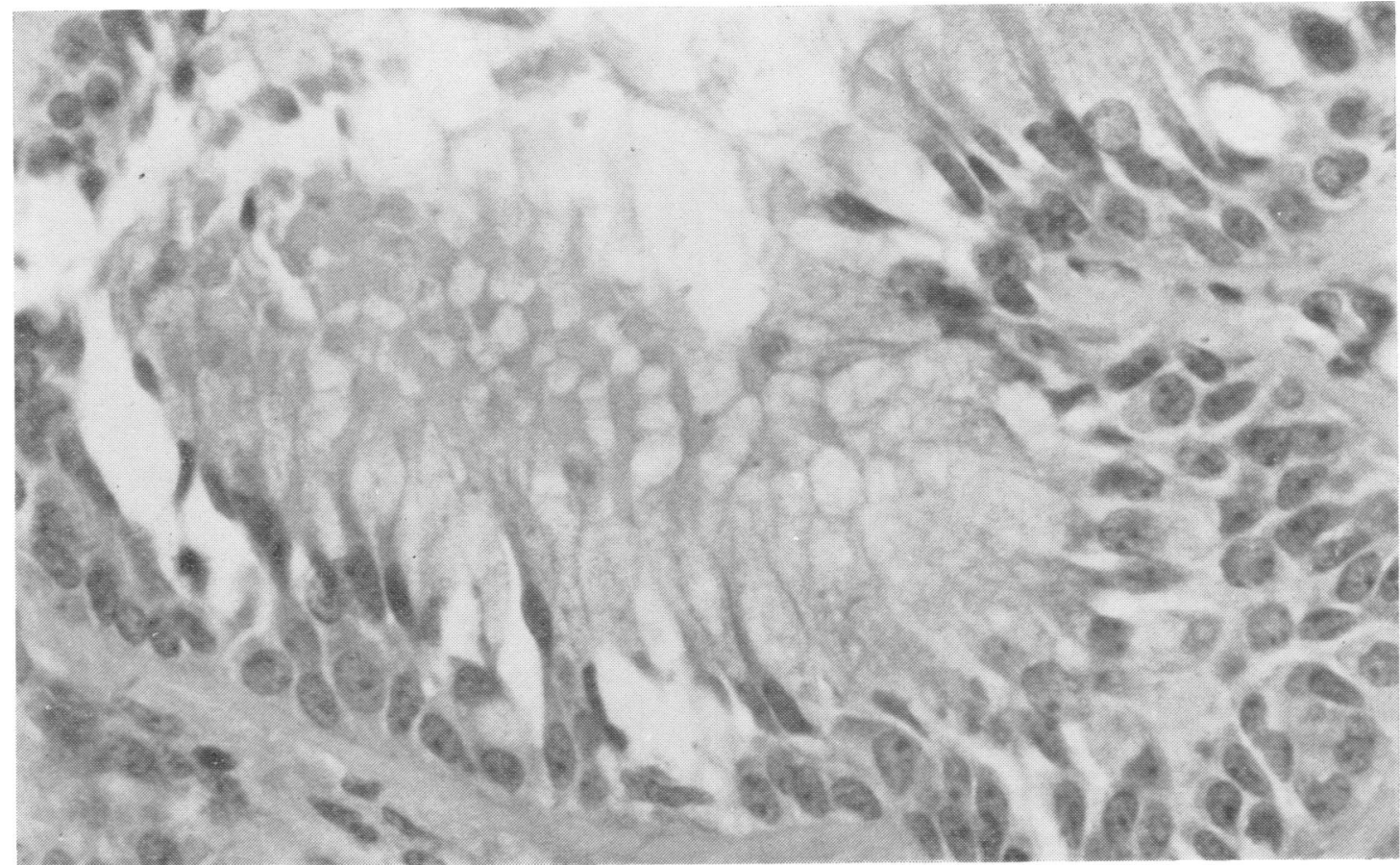

Fig. 3 Section of olfactory epithelium (case 1). Stained with phloxine tartrazine, original magnification $\times 650$, showing nearly normal epithelium with a microcyst on the upper right and ragged epithelium containing nuclear inclusion bodies elsewhere.

side of the crista galli. Mucosa and bone of the nasal septum and superior and middle conchae of the upper third of the nasal cavity were attached, as well as parts of the ethmoid sinuses. Olfactory mucosa from several patients dying from other diseases was also examined.

The olfactory mucosa was inflamed, and in the third patient it was purple. It contained a vesicle in each patient of 4-7 $\mathrm{mm}$ diameter. Herpes simplex virus was grown from the vesicle in casses 1 and 3 , and from the olfactory bulb just above the vesicle in case 2 . Virus isolation from the vesicle or mucosa was not attempted in the latter patient so that the specimen might be preserved better for photography and histology.

The histological abnormalities were very similar in each patient with stretches of normal and abnormal epithelium and ulcerated olfactory mucosa. The earliest changes in the epithelium were a loss of tight junctions between cells, associated with nuclear inclusion bodies staining red with phloxine tartrazine. Small vesicles appeared in the epithelium, only distinguished from histological artefact by the surrounding nuclear inclusion bodies. Vesicles bursting through the surface separated the cells, giving the epithelium a ragged appearance, and swollen dying cells separated to join the mass of necrotic epithelial debris in the respiratory space. In some areas the lamina propria was denuded of epithelium over stretches up to a centimetre long, and in others only a single layer of basal cells remained. Cases 1 and 3, who survived into the third week of their illness, showed short stretches of lamina propria covered by non-keratinising stratified squamous epithelium. Some squamous cells contained two nuclei and many showed swollen watery cytoplasm and nuclei with nuclear inclusion bodies, changes typical of "ballooning degeneration" seen in herpes simplex infection of stratified squamous epithelium (Rook et al., 1968). In the lamina propria Bowman's glands were much less affected than the olfactory epithelium but in a few the cells showed nuclear inclusions, swelling of the cytoplasm and nuclei, and microcysts between the cells obliterating the lumen. Collections of small mononuclear cells, chiefly lymphocytes and plasma cells, were present in the lamina propria and were plentiful beneath the ulcers. The tissue was very oedematous and 


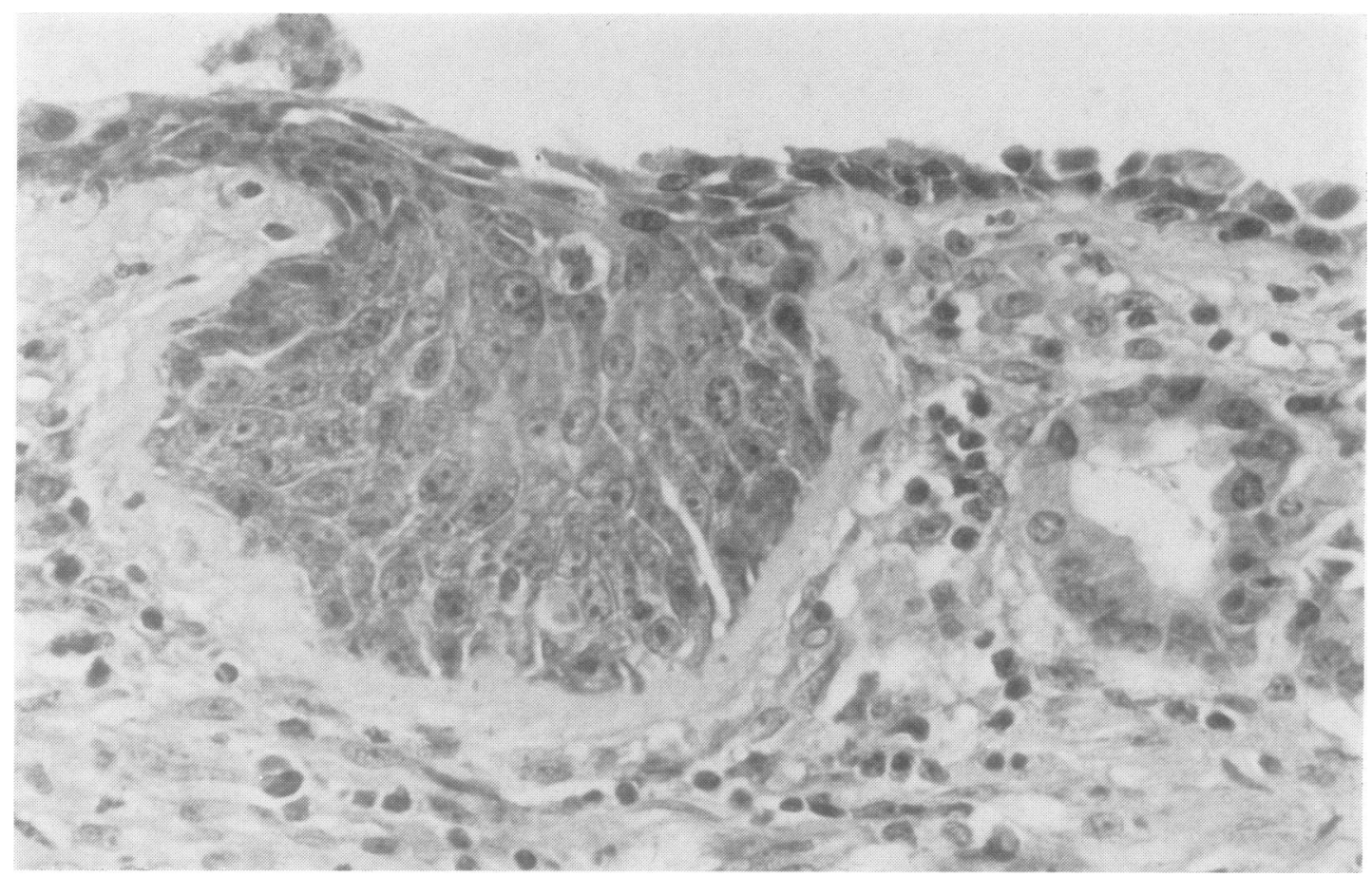

Fig. 4 Section of olfactory epithelium (case 1) stained with phloxine tartrazine, original magnification $\times 650$, showing squamous metaplasia with ballooning degeneration of the cells which contain nuclear inclusion bodies.

the lymphatic spaces were dilated. The vesicles seen naked eye were not in the epithelium, as in herpes simplex infection of the skin, but were collections of fluid within the lamina propria. In the cases 2 and 3 small haemorrhages were found both within the lamina propria and within the perineural sheaths of a few olfactory nerves.

Areas containing epithelium and olfactory nerves were dissected out from paraffin blocks and were prepared for electron microscopy using the method described by Robinson (1977). Unfortunately, prolonged decalcification in Jenkins' solution had damaged the tissue so badly that it was impossible to identify virus particles.

\section{Discussion}

We interpret these changes as an indication of herpes simplex infection of the olfactory mucosa. The haemorrhages within the perineurial sheaths of olfactory nerves at least suggest that the virus travelled through them. While it is possible from our evidence that the virus travelled from the brain to the olfactory mucosa, the localisation of early lesions of herpes simplex encephalitis in the limbic system makes it much more likely that infection of the olfactory mucosa precedes the encephalitis. In some patients the infection may remain localised in the olfactory epithelium. It is difficult to inspect or to biopsy olfactory mucosa during life because the olfactory space is too narrow. Anosmia may be found in patients surviving the disease (Drachman and Adams, 1962). This may be caused by destruction either of the olfactory epithelium or of the central connections of the olfactory cells, or both.

\section{References}

Drachman, D. A., and Adams, R. D. (1962). Herpes simplex and acute inclusion body encephalitis. Archives of Neurology (Chicago), 7, 61-79.

Flewitt, T. H. (1973). The rapid diagnosis of herpes encephalitis. Postgraduate Medical Journal, 49, 398-400.

Hurst, E. W. (1936). The newer knowledge of virus diseases of the nervous system: a review and an interpretation. Brain, 59, 1-34.

Johnson, R. T., and Mims, C. A. (1968). Pathogenesis of viral infections of the nervous system. New England Journal of Medicine, 278, 23-30. 
Legg, N. (1975). How viruses affect the central nervous system. In Modern Trends in Neurology, vol. 6, p. 114. Edited by D. Williams. Butterworth: London.

Robinson, G. (1977). In The Theory and Practice of
Histological Techniques, p. 33. Edited by J. D. Bancroft and A. Stevens. Livingstone: Edinburgh.

Rook, A., Wilkinson, D. S., and Ebling, F. J. G. (1968). Textbook of Dermatology, second edition, pp. 52-56. Blackwell: Oxford. 